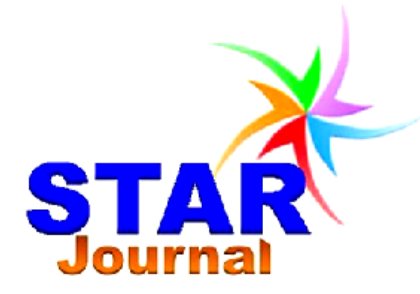

ISSN: 2226-7522(Print) and 2305-3327 (Online) Science, Technology and Arts Research Journal Jan-March 2012, 1(1): 10-17 www.starjournal.org Copyright@2012 STAR. All Rights Reserved

\title{
Development of New Formulation for Mouth Disintegrating Tablets of Metoclopramide by Sublimation Method
}

\author{
Ram Mohan Gupta V', Halakatti PK $^{2^{\star}}$, Lakshmi Narasu $\mathbf{M}^{3}$, Chandrashekhar VM² \\ ${ }^{1}$ Pullareddy College of Pharmacy, Jinnaram, Medak (District), Andhra Pradesh, India \\ ${ }^{2}$ H.S.K College of Pharmacy, B.V.V.S. Campus, Bagalkot-587101, Karnataka, India \\ ${ }^{3}$ Center of Biotechnology, Institute of Science and Technology, JNTU, Hyderabad-500072, \\ Andhra Pradesh, India
}

\begin{tabular}{|c|c|}
\hline Abstract & Article Information \\
\hline $\begin{array}{l}\text { The main purpose of the present research work was to mask the bitter taste of } \\
\text { the active drug and to formulate the MD tablets by sublimation method. } \\
\text { Metoclopramide } \mathrm{HCl} \text { tablets were prepared by masking the bitter taste with the } \\
\text { help of Eudragit E-100, then preparing the tablets by using subliming agents i.e. } \\
\text { camphor and ammonium bicarbonate. The formulations were evaluated for } \\
\text { weight variation, hardness, friability, drug content, wetting time, In vitro } \\
\text { disintegration time and In vivo dispersion, mouth feel and in vitro dissolution } \\
\text { studies. All the formulations comply with the test for weight variation as per } \\
\text { Indian Pharmacopeia (IP) and found to be within the limits. The drug content of } \\
\text { all the formulations was within the acceptable limits. Disintegration time of all } \\
\text { the formulations was found less than } 1 \text { min. Wetting time values were giving } \\
\text { direct relation to the disintegration time values because by increasing tablet } \\
\text { porosity, more water can be absorbed. The best formulation showed good } \\
\text { release profile with maximum drug being released at all time intervals. The } \\
\text { present research work helped in understanding the effect of formulation } \\
\text { processing variables especially the subliming agent on the drug release profile } \\
\text { for MD tablets. The present study demonstrated good potentials in quick } \\
\text { absorption, improved bioavailability and patient compliance. }\end{array}$ & $\begin{array}{l}\text { Article History: } \\
\text { Received : 05-01-2012 } \\
\text { Revised : 10-02-2012 } \\
\text { Accepted : 13-02-2012 } \\
\text { Keywords: } \\
\text { Metoclopramide HCl } \\
\text { Camphor } \\
\text { Ammoniumbicarbonate } \\
\text { Mouth disintegrating } \\
{ }^{*} \text { Corresponding Author: } \\
\text { Prabhu K. Halakatti } \\
\text { E-mail: } \\
\text { prabhuhalakatti52@gmail.com } \\
\text { Phone: +91 9739459637 }\end{array}$ \\
\hline
\end{tabular}

\section{INTRODUCTION}

Oral delivery is currently the gold standard in the pharmaceutical industry where it is regarded as the safest, most convenient and most economical method of drug delivery having the highest patient compliance (Bhowmik, 2009). Many patients have difficulty swallowing tablets and hard gelatin capsules and consequently do not take medications as prescribed. It is estimated that $50 \%$ of the population is affected by this problem, which results in a high incidence of noncompliance and ineffective therapy (Luca, 2001). Elderly patients may find the administration of the conventional oral dosage forms difficult as they regularly require medicines to maintain a healthy life (Hanawa, 1995). Children may also have difficulty in ingesting because of their underdeveloped muscular and nervous systems (Porter, 2001). Drinking water plays an important role in the swallowing of oral dosage forms. Often times people experience inconvenience in swallowing conventional dosage forms such as tablet when water is not available, in the case of the motion sickness (kinetosis) and sudden episodes of 
Ram Mohan Gupta et al.,

coughing during the common cold, allergic condition and bronchitis (Sagar, et al., 2011).

Unfortunately, majority of the drugs have a natural bitter taste that can create a burning feeling in the throat or in the mouth. In particular, a bitter taste can decrease the patient compliance and thus reducing an effective pharmacotherapy. In order to achieve an acceptable palatability, the addition of flavors or sweeteners is limited and may not be efficient enough to mask the taste buds of drugs and requires the use of technological processes (Pankaj, 2010). Thus a number of taste masking technologies like use of ion exchange resins, the inclusion complexes with cyclodextrins, melt granulation and also Eudragit E-100.

Methods to improve patient's compliance have always attracted scientists towards the development of fancy oral drug delivery systems. Among them, mouth dissolving drug delivery systems (MDDDS) have acquired an important position in the market by overcoming previously encountered administration problems and contributing to extension of patent life (Shukla et al., 2009).

MDDT's disintegrated and/or dissolve rapidly in the saliva without the need for water. Some tablets are designed to dissolve in saliva remarkably fast, within a few seconds, and are true fast-dissolving tablets (Bhupendra and Nayan, 2009).

Metoclopramide hydrochloride has got central antidopaminergic effect and is used mainly as antiemetic and antinauseant. Chemically, metoclopramide is 4-amino-5-chloro- $\mathrm{N}-[(2$ diethylamino) ethyl]- 2-methoxy benzamide (Budavari, 2001)

Thus in our present study, the bitter taste of the drug (Metoclopramide $\mathrm{HCl}$ ) was masked by forming the granules with the Eudragit E-100, and the MD tablets were prepared by sublimation method for better patient compliance.

\section{MATERIALS AND METHODS}

\section{Materials}

Metoclopramide $\mathrm{HCl}$ was obtained from Elvina Pharmaceuticals Pvt. Ltd., Dharwad. Eudragit E-100 obtained as a gift sample from Degussa Pvt. Ltd Mumbai. Ammonium bicarbonate and camphor were purchased from
Sci. Technol. Arts Res. J., Jan-March 2012; 1(1): 10-17

S.D. Fine Chemicals Ltd., Mumbai. Mannitol was purchased from Loba Fine Chemicals, Mumbai. Aspartame was gift sample from Micro Lab Ltd., Bangalore. Trusil Orange and Peppermint DC (IFF) were kindly supplied by Indoco Remedies, Goa. All other ingredients were used of analytical grade.

\section{Taste Masking of Drug by Eudragit E-100}

Here in our present study, first the bitter drug Metoclopramide $\mathrm{HCl}$ was properly mixed with the suitable different proportion (Drug: polymer ratio 1:1, 1:2, 1:3, 1:4) of Eudragit E-100. Then the $10 \%$ ethanol is added to the mixture of drug with Eudragit E-100 in the beaker. Then a gel containing the mixture of the drug and Eudragit $\mathrm{E}-100$ was prepared; using this prepared gel, the taste masked granules were prepared by the extrusion method. The prepared gel was manually pressed out using a syringe. After extrusion of the gel, ethanol was removed by evaporation overnight at room temperature and subsequently the solidified gel in the shape of a string was crushed into granules using the mortar and pestle (Tatsuya, 1999). The prepared taste masked granules were sieved at $60 \mathrm{\#}$ and used for further studies.

\section{Preparation of MD Tablets}

All the ingredients were sieved through 60\# sieve. The subliming agents camphor and ammonium bicarbonate were used in different varying amounts $(5 \%, 10 \%, 15 \%, 20 \%, 25 \%)$ separately, the taste masked granules (Drug: Eudragit E-100 ratio 1:2), Mannitol and Avicel PH 102 were mixed together. Then aspartame as sweetening agent, Trusil Orange and Peppermint DC (IFF) as flavouring agent were mixed and magnesium stearate with talc as a flow promoter was added lastly and mixed properly. The mixture was compressed into $200 \mathrm{mg}$ tablets using flat face round $8 \mathrm{~mm}$ on rotary tablet machine. Drug containing subliming agents were then placed in an oven at $60{ }^{\circ} \mathrm{C}$ to eliminate the subliming agents by sublimation (Koizumi et.al., 1997). A sample of 20 tablets was labeled and weighed before and after sublimation of subliming agents to determine the weight loss. Five formulations were prepared for each subliming agents, camphor as named as MEC and ammonium bicarbonate as MEN.

\section{Angle of Repose}

Angle of repose was determined using funnel method. The blend was poured through funnel that can be raised vertically until a maximum cone height $(h)$ was obtained. Radius of the 
heap ( $r$ ) was measured and angle of repose was calculated using the formula,

$$
\theta=\tan ^{-1} \frac{h}{r}
$$

Where, $\theta$ is the angle of repose, $h$ is height of pile; $r$ is radius of the base of pile.

\section{Bulk Density}

Apparent bulk density was determined by pouring presieved drug excipient blend into a graduated cylinder and measuring the volume and weight "as it is". It is expressed in $\mathrm{g} / \mathrm{ml}$ and is given by

LBD (Loose Bulk Density) $=\frac{\text { Mass of Powder }}{\text { Volume of Packing }}$

\section{Tapped Density}

It was determined by placing a graduated cylinder, containing a known mass of drugexcipient blend, on mechanical tapping apparatus. The tapped volume was measured by tapping the powder to constant volume. It is expressed in $\mathrm{g} / \mathrm{ml}$ and is given by

$$
\operatorname{TBD}\left(\text { Tapped Bulk Density) }=\frac{\text { Mass of Powder }}{\text { Tapped Volume of Packing }}\right.
$$

\section{Powder Flow Properties}

The flow properties were determined by Carr's Index (I) and it is expressed in percentage and is expressed by

$$
\text { Carr's Index } \%=\frac{\text { TBD }- \text { LBD } \times 100}{\text { TBD }}
$$

\section{Post - Compression Parameters}

Uniformity of thickness, hardness, friability test, weight variation test and drug content uniformity were performed for all the prepared formulations according IP (1996) specifications. The other different evaluation parameters procedure were briefly explained below

\section{Wetting Time}

The method was applied to measure tablet wetting time. A piece of tissue paper folded twice was placed in a small petridish (i.d. $=6.5$ $\mathrm{cm}$ ) containing $6 \mathrm{ml}$ of water, a tablet was put on the paper, and the time for complete wetting
Sci. Technol. Arts Res. J., Jan-March 2012; 1(1): 10-17

was measured. Three trials for each batch were performed and standard deviation was also determined (Yunxia et al., 1996).

\section{In vitro Dispersion Time}

In vitro dispersion time was measured by dropping a tablet in a measuring cylinder containing $10 \mathrm{ml}$ of $\mathrm{pH} 6.8$ (simulated saliva fluid). Three tablets from each formulation were randomly selected and in vitro dispersion time was performed. Standard deviation was also determined and in vitro dispersion time is expressed in seconds.

\section{In vitro Disintegration Test}

The process of breakdown of a tablet into smaller particles is called as disintegration. The in vitro disintegration time of a tablet was determined using disintegration test apparatus as per IP specifications.

Place one tablet in each of the 6 tubes of the basket. Add a disc to each tube and run the apparatus using pH 6.8 (simulated saliva fluid) maintained at $37 \pm 2{ }^{\circ} \mathrm{C}$ as the immersion liquid. The assembly should be raised and lowered between 30 cycles per minute in the $\mathrm{pH} 6.8$ maintained at $37 \pm 2{ }^{\circ} \mathrm{C}$. The time in seconds taken for complete disintegration of the tablet with no palpable mass remaining in the apparatus was measured and recorded.

\section{Mouth feel and Disintegration in the Oral Cavity Mouth feel}

To know mouth feel of the tablets, the same human volunteers held the disintegrated particles in the mouth for 30 seconds and the taste sensation felt was recorded.

\section{In Vivo Disintegration Time}

Three healthy human volunteers, whose informed consent was first obtained, were selected for the study. Each volunteer randomly took one tablet from each formulation and kept on the tongue. The time taken for complete disintegration of the tablet on the tongue was noted. It is expressed in seconds. After the test, mouth was washed with distilled water. 3 trials were performed at different time intervals. 
Table 1. Evaluation of pre-compression parameters.

\begin{tabular}{ccccc}
\hline $\begin{array}{c}\text { Formulation } \\
\text { Code }\end{array}$ & $\begin{array}{c}\text { Angle of } \\
\text { Repose } \\
(\boldsymbol{\theta})\end{array}$ & $\begin{array}{c}\text { Loose Bulk } \\
\text { Density } \\
\left(\mathbf{g m} / \mathbf{c m}^{\mathbf{3}}\right)\end{array}$ & $\begin{array}{c}\text { Tapped Bulk } \\
\text { Density } \\
\left(\mathbf{g m} / \mathbf{c m}^{\mathbf{3}}\right)\end{array}$ & $\begin{array}{c}\% \\
\text { Compressibility }\end{array}$ \\
\hline MEC1 & 32.83 & 0.59 & 0.70 & 15.69 \\
MEC2 & 32.83 & 0.55 & 0.63 & 12.73 \\
MEC3 & 25.56 & 0.51 & 0.61 & 16.95 \\
MEC4 & 30.96 & 0.46 & 0.56 & 18.18 \\
MEC5 & 29.74 & 0.53 & 0.61 & 14.04 \\
MEN1 & 30.57 & 0.50 & 0.61 & 18.00 \\
MEN2 & 29.06 & 0.51 & 0.59 & 13.52 \\
MEN3 & 28.73 & 0.55 & 0.64 & 14.55 \\
MEN4 & 30.38 & 0.58 & 0.67 & 13.46 \\
MEN5 & 29.05 & 0.54 & 0.64 & 15.22 \\
\hline
\end{tabular}

Table 2. Evaluation of post-compression parameters.

\begin{tabular}{ccccc}
\hline $\begin{array}{c}\text { Formulation } \\
\text { Code }\end{array}$ & $\begin{array}{c}\text { Uniformity of } \\
\text { Thickness } \\
(\mathbf{n = 3})(\mathbf{m m})\end{array}$ & $\begin{array}{c}\text { Friability } \\
\mathbf{\%}\end{array}$ & $\begin{array}{c}\text { Weight } \\
\text { Variation } \\
(\mathbf{n = 1 0})(\mathbf{m g})\end{array}$ & $\begin{array}{c}\text { Drug Content } \\
\text { Uniformity } \\
(\mathbf{n = 3})(\mathbf{m g})\end{array}$ \\
\hline MEC1 & $3.30 \pm 0.000$ & 0.6535 & $201.16 \pm 1.49$ & $96.20 \pm 0.5204$ \\
MEC2 & $3.37 \pm 0.100$ & 0.6991 & $199.84 \pm 1.45$ & $99.25 \pm 0.7603$ \\
MEC3 & $3.43 \pm 0.116$ & 0.7711 & $201.00 \pm 1.46$ & $99.79 \pm 0.1909$ \\
MEC4 & $3.40 \pm 0.000$ & 0.8132 & $198.85 \pm 1.46$ & $98.65 \pm 0.6519$ \\
MEC5 & $3.60 \pm 0.100$ & 0.9054 & $201.42 \pm 1.81$ & $99.00 \pm 0.8197$ \\
MEN1 & $3.50 \pm 0.000$ & 0.7489 & $199.89 \pm 1.67$ & $97.13 \pm 0.7906$ \\
MEN2 & $3.43 \pm 0.058$ & 0.6109 & $200.83 \pm 1.81$ & $98.50 \pm 0.6960$ \\
MEN3 & $3.57 \pm 0.116$ & 0.6766 & $201.18 \pm 1.44$ & $99.38 \pm 0.3750$ \\
MEN4 & $3.53 \pm 0.058$ & 0.8278 & $199.94 \pm 1.88$ & $98.55 \pm 0.4155$ \\
MEN5 & $3.57 \pm 0.058$ & 0.8836 & $198 . .02 \pm 1.44$ & $97.38 \pm 0.6614$ \\
\hline
\end{tabular}

\section{In vitro Dissolution Studies}

The release rate of prepared tablet was determined using USP dissolution testing apparatus II (paddle type). The dissolution test was performed using $900 \mathrm{ml}$ of $0.1 \mathrm{~N} \mathrm{HCl}$, at $37 \pm 0.5{ }^{\circ} \mathrm{C}$ and at $50 \mathrm{rpm}$, suitable sample was withdrawn from the dissolution apparatus, and it was replaced with fresh dissolution medium. Absorbance of these solutions was measured at $273 \mathrm{~nm}$ UV spectrophotometer (USP, 2000).

\section{Stability Studies}

In the present study, stability studies were carried out at $25^{\circ} \mathrm{C} / 60 \% \mathrm{RH}$ and $40{ }^{\circ} \mathrm{C} / 75 \% \mathrm{RH}$ for a specific time period according to the $\mathrm{ICH}$ guidelines (Natalie, 1997).

\section{RESULTS AND DISCUSSION}

Many patients, especially elderly find it difficult in swallowing tablets, capsules, fluids and thus do not comply with prescription, which results in high incidence of non-compliance oriented research has resulted in bringing out many safer and newer drug delivery systems. Rapidly disintegrating/dissolving tablet is one of such example, for the reason of rapid disintegration or even with saliva. Significance of this drug delivery system includes administration without water, accuracy of 
Table 3. Wetting, In vitro disintegration, In vitro dispersion and In vivo Disintegration time.

\begin{tabular}{cccccc}
\hline $\begin{array}{c}\text { Formulation } \\
\text { Code }\end{array}$ & $\begin{array}{c}\text { Wetting } \\
\text { time }\end{array}$ & $\begin{array}{c}\text { In vitro } \\
\text { Disintegration } \\
\text { Time }\end{array}$ & $\begin{array}{c}\text { In vitro } \\
\text { Dispersion } \\
\text { Time }\end{array}$ & $\begin{array}{c}\text { In vivo } \\
\text { Disintegration }\end{array}$ & $\begin{array}{c}\text { Mouth } \\
\text { Feel }\end{array}$ \\
\hline MEC1 & $54.00 \pm 0.00$ & $42.00 \pm 0.00$ & $49.33 \pm 0.58$ & $60.00 \pm 0.00$ & + \\
MEC2 & $46.33 \pm 0.58$ & $38.00 \pm 1.00$ & $40.67 \pm 1.53$ & $53.33 \pm 0.58$ & + \\
MEC3 & $39.67 \pm 0.58$ & $36.33 \pm 0.58$ & $35.33 \pm 0.58$ & $44.00 \pm 0.00$ & + \\
MEC4 & $37.33 \pm 0.58$ & $32.33 \pm 0.58$ & $37.33 \pm 0.58$ & $41.00 \pm 1.00$ & + \\
MEC5 & $35.67 \pm 0.58$ & $34.00 \pm 0.58$ & $33.33 \pm 1.53$ & $38.33 \pm 1.53$ & + \\
MEN1 & $44.00 \pm 0.00$ & $42.00 \pm 0.00$ & $49.33 \pm 0.58$ & $57.00 \pm 0.00$ & + \\
MEN2 & $38.33 \pm 0.58$ & $36.00 \pm 1.00$ & $40.67 \pm 1.53$ & $45.33 \pm 0.58$ & + \\
MEN3 & $30.67 \pm 0.58$ & $29.33 \pm 0.58$ & $34.33 \pm 0.58$ & $38.00 \pm 0.00$ & + \\
MEN4 & $39.33 \pm 0.58$ & $35.33 \pm 0.58$ & $42.33 \pm 0.58$ & $44.00 \pm 1.00$ & + \\
MEN5 & $28.67 \pm 0.58$ & $34.33 \pm 0.58$ & $37.33 \pm 1.53$ & $42.33 \pm 1.53$ & + \\
\hline
\end{tabular}

"+" Good mouth feel

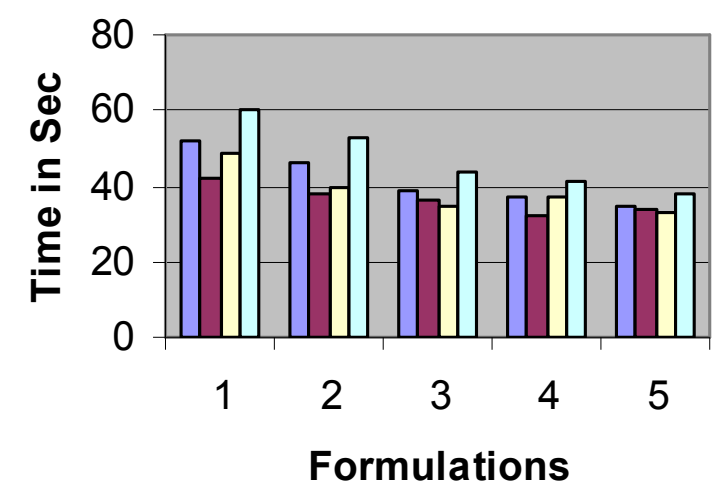

\begin{tabular}{|l|}
$\square$ Wetting time \\
$\square$ In vitro \\
disintegration time \\
$\square$ In vitro dispersion \\
time \\
$\square$ In vivo disintegrtion \\
time
\end{tabular}

Figure 1. Comparison of wetting, In vitro disintegration, In vitro dispersion and In vivo Disintegration time for camphor formulations.

dosage, ease of portability, alternative to liquid dosage forms, ideal for paediatric and geriatric patients and rapid onset of action (Seager, 1998 and Habib et al., 2000).

Mouth dissolving tablets are also called as rapidly dissolving, rapidly disintegrating, orodispersible, orally disintegrating, fast dissolving, fast disintegrating tablets. These tablts shows better patinet compliance, improved bioavailablity and dissolution rate, and observes maximum stability.

In our present study, the granules were formed by masking bitter taste of the drug was masked with Eudragit E-100 and then granules were mixed with the subliming agents i.e. camphor and ammonium bicarbonate separately and other ingredients were mixed and the tablets were prepared.

\section{Evaluation of Pre-compression Properties}

For all the prepared formulation, blend of drug and excipients was prepared and evaluated for pre-compression properties shown in Table 1. For camphor formulations the Bulk density was found between 0.46 to $0.59 \mathrm{gm} / \mathrm{cm}^{3}$, tapped density between 0.56 to $0.70 \mathrm{gm} / \mathrm{cm}^{3}, \%$ compressibility found to be 12.73 to 18.18 and angle of repose found to 29.74 to 32.83 . For ammonium bicarbonate formulations bulk density found between 0.50 to $0.58 \mathrm{gm} / \mathrm{cm}^{3}$, tapped density between 0.59 to $0.67 \mathrm{gm} / \mathrm{cm}^{3}, \%$ compressibility found to be 13.46 to 18.00 and angle of repose found to 29.05 to 30.57 . All the formulation shows the fair to good flow 


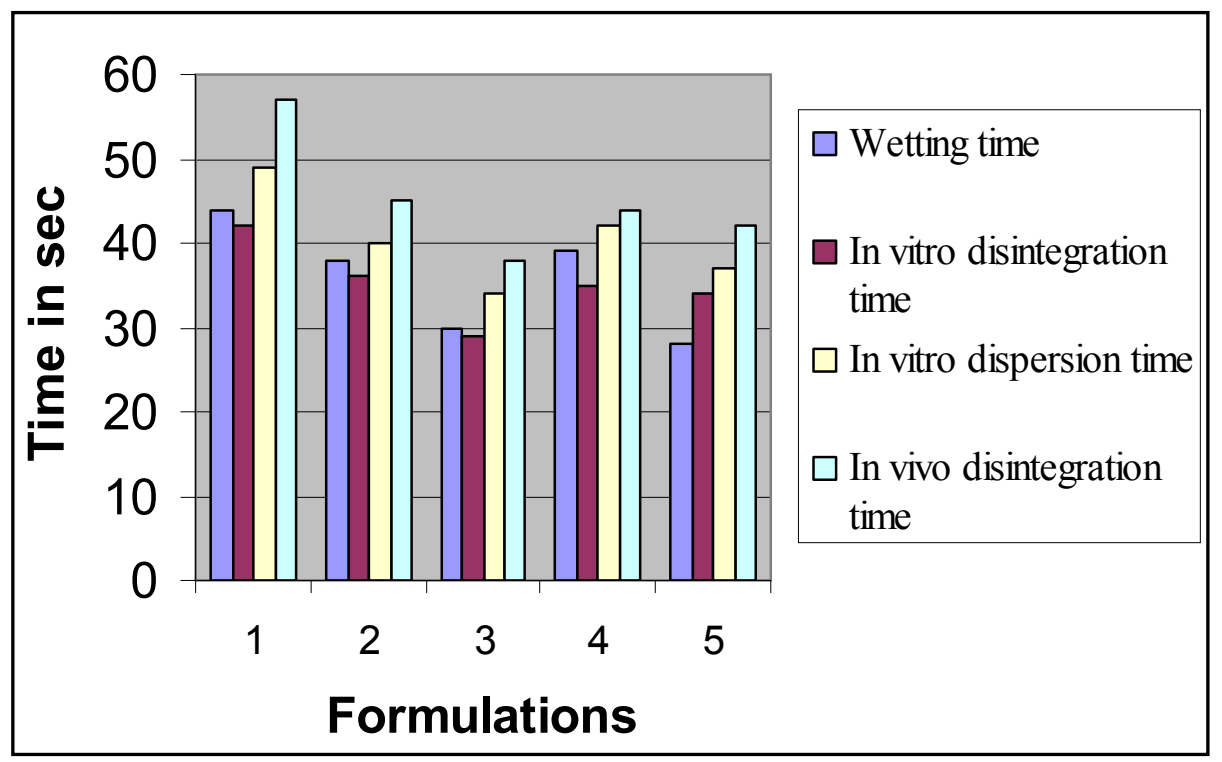

Figure 2. Comparison of wetting, In vitro disintegration, In vitro dispersion and In vivo disintegration time for Ammonium bicarbonate formulations.

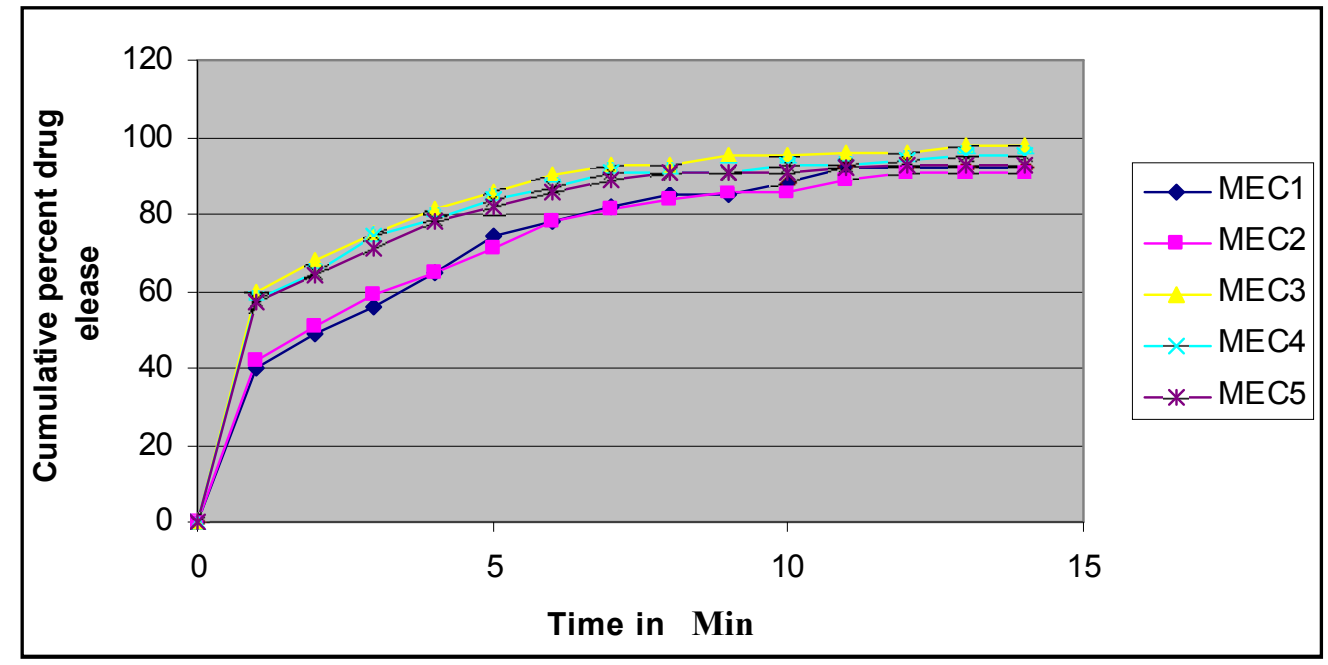

Figure 3. Drug release profile of Camphor formulations.

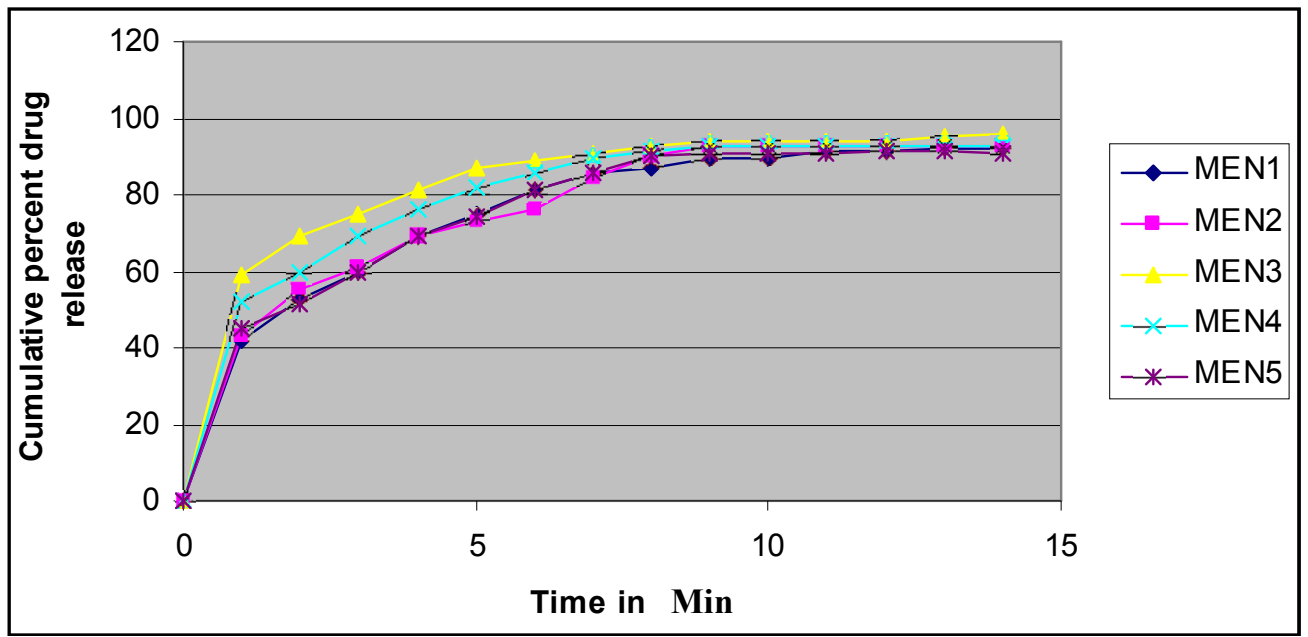

Figure 4. Drug release profile of Ammonium bicarbonate formulations. 
Ram Mohan Gupta et al.,

properties for direct compression and hence tablets were prepared by using direct compression.

\section{Evaluation of Post Compression Properties}

The mouth disintegrating tablets were prepared by direct compression method. The different post compression parameters were evaluated. Friability of the tablets was found below $1 \%$ indicating a good mechanical resistance of tablets. Uniformity of thickness, drug content, weight variation results were depleted in the Table 2. Hardness of both different subliming agents formulations found between 2.5 to $3.5 \mathrm{~kg} / \mathrm{cm}^{2}$.

FTIR study reveals that there was no interaction between drug and excipients for all the formulations.

Wetting time is closely related to the inner structure of the tablet. Due to formation of the porous structure in the tablet, the wetting of the tablet leads faster as the concentration of the subliming agent increases. This experiment mimics the action of saliva in contact with the tablet to illustrate the water uptake and subsequent wetting of tablet. This showed that wetting process was very rapid in almost all formulations. This may be due to presence of maximum number of pores leads to ability of wetting and also capacity of water absorption.

In vitro dispersion and in vitro disintegration time were carried for all the formulations and results were depicted in the Table 3 . Dispersiblity and disintegration was faster as the porous nature of the tablets. High porosity was greater as the concentration of the subliming agent increases. This porosity nature helps in disintegration and dispersion of the tablet. In all the formulations, tablets had high porosity and consequently lower wetting times. In this addition, the wetting time values were giving direct relation to the disintegration time values because by increasing tablet porosity, more water can be absorbed easily, facilitating tablet breakdown. In vivo disintegration study also performed by keeping the tablet in the human volunteer mouth and results were depicted in Table 3. Thus oral disintegration values of tablet were higher than those of the in vitro values, thus this may be due to smaller volume of water in the oral cavity. Comparison study also carried out for In vitro dispersion, In vitro disintegration, In vivo disintegration and wetting time and shown in figure 1 and 2.
Sci. Technol. Arts Res. J., Jan-March 2012; 1(1): 10-17

As the concentration of camphor and ammonium bicarbonate increases, there will be more number of pores formations in the tablet, ultimately water/ saliva can enter and absorb more quantity, which will lead to rapid disintegration. Another ingredient which is included in the formulations is avicel $\mathrm{PH} 102$, which is also responsible for disintegration of tablet.

The healthy human volunteers participated in taste evaluation test, were asked to give their opinion about the feeling of smoothness or grittiness of the dispersion soon after the tablet got disintegrated. All the formulations show smooth and pleasant mouth feeling, thus fulfill the requirements of MD tablets.

In vitro release studies were carried out using USP tablet dissolution test apparatus paddle method at $37 \pm 0.5^{\circ} \mathrm{C}$, taking $900 \mathrm{ml}$ of $0.1 \mathrm{~N} \mathrm{HCl}$ as dissolution medium. Speed of rotation of the paddle was set at $50 \mathrm{rpm}$. Aliquots of $1 \mathrm{ml}$ were withdrawn at different time interval and replaced from fresh dissolution medium and analyzed spectrophotometrically at $273 \mathrm{~nm}$. All formulations showed more than $90 \%$ within 10 min. The in vitro dissolution profile indicated faster and maximum drug release from formulation MEN3, MEC3 and MEC4. The release profile was shown in Figure 3 and 4

The optimized formulations were selected on the basis of hardness, friability, and drug content and disintegration time and drug release. The selected formulations (MEC3, MEC4 and MEN3) were found stable and not much difference in the results after studying the different parameters.

\section{CONCLUSION}

From the results obtained, it can be concluded that the MD tablets can be prepared by sublimation method. Eudragit E-100 can be used for masking the bitter taste in the ratio of 1:2. Physical properties of all prepared tablets formulations were acceptable. A high porosity was achieved due to formation of many pores after removal of sublimable materials. Drug release also found maximum within short period. The prepared tablet gives benefit in terms of patient compliance, rapid onset of action, increased bioavailability, low side effect and good stability which make these tablets popular as a dosage form. 
Ram Mohan Gupta et al.,

\section{REFERENCES}

Banker, S.G., Anderson, S.N. (1991). Section III Pharmaceutical dosage forms. In: Libermann, H.A. and Kanin. M, (Eds.) Bombay, Vergese publishing house. Pp. 293-345.

Bhowmik, D., Chiranjib,B., Krishnakanth, Pankaj, Margret, C.R. (2009). Fast dissolving tablet: An overview. Journal of Chemical and Pharmaceutical Research 1: 163-177.

Bhupendra, G. P., Nayan, R. (2009). A review on recent patents on fast dissolving drug delivery system. International Journal of PharmTech Research 1(3): 790-798.

Budavari, S.(2001). The Merck Index, 13 ${ }^{\text {th }}$ Edn., Merck and Co. Inc., Whitehouse Station, NJ. Pp1094.

Habib, W., Khankari, R and Hontz, J. (2000). Fast dissolving drug delivery systems, critical review in therapeutics. Drug Carrier System 17(1): 61-72.

Hanawa, T. (1995). New oral dosage for elderly patients: preparation and characterization of silk fibrion gel. Chemical and Pharmaceutical Bulletin 43: 284-288.

In vitro dissolution (2000). The United States Pharma -copoeia, United states Pharmacy convention. Asian edition. Pp1941-1946.

Koizumi, K., Watanabe, Y., Morita, K., Utoguchi, N., Matsumoto, M. (1997). New method fof preparing high porosity rapidly salva soluble compressed tablets using mannitol with camphor, asubliming material. International Journal of Pharmaceutics 152: $127-131$.

Leon, L., Habert, A. L., Joseph L.K. The Theory and Practice of Industrial Pharmacy, $3^{\text {rd }}$ Edition, Verghese publishing house, Mumbai. Pp. 67-71, Pp. 296-302.

Luca, D. (2001). Fast melting tablets: Developments and technologies. Pp 44-50.

Natalie, M.C. (1997). Stability studies in overview of $\mathrm{ICH}$ guidelines for drug products. Matrix Pharmaceutical Inc.

Pankaj, P.A., Sanjay B.P., Abhijeet, N.T., Manoj, A.W., Parag, D.K., Rajendra, K.S. (2010). Design and evaluation of taste masked chewable dispersible tablet of lamotrigine by melt granulation. International Journal of Drug Delivery 2: 188-196.

Porter, S.C. (2001). Novel drug delivery: Review of recent trends with oral solid dosage forms. American Pharmaceutical Review 4: 28-35.

Sagar A.K., Prafulla, S.C., Rajesh, J.O., Sandip, S.K., Rishikesh, V.A., Trushal, V.C. (2011). Mouth dissolving tablets: An innovative technology. International Journal of Applied Biology and Pharmaceutical Technology 2(1): 496-503:
Sci. Technol. Arts Res. J., Jan-March 2012; 1(1): 10-17

Seager, H. (1998). Drug delivery products and the zydis fast dissolving dosage forms, Journal of Pharmacy and Pharmacology 50(4): 375-382.

Shukla,D., Subhashis, C., Sanjay, S., Brahmeshwar, M. (2009). Mouth Dissolving Tablets I: An overview of formulation technology. Scientia Pharmaceutica 77: 309-326

Yunxia, B.H.., Yorinobu, Y., Kazumi,D., Akinobu, O.K.(1996) Preparation and evaluation compressed tablet rapidly disintegrating in the oral cavity. Chemical and Pharmaceutical Bulletin 44: 2121-2127. 